\title{
A Summary of Research on the Durability of Cemented Paste Backfill in Mines
}

\author{
$\mathrm{Hao} \mathrm{Li}$ \\ College of mining and safety \\ engineering \\ Shandong University of Science and \\ Technology \\ Qingdao, China \\ 15762284597@163.com \\ Yalan Guo \\ College of mining and safety \\ engineering \\ Shandong University of Science and \\ Technology \\ Qingdao, China \\ 1457478854@qq.com
}

\author{
Yin Liu \\ College of mining and safety \\ engineering \\ Shandong University of Science and \\ Technology \\ Qingdao, China \\ liuyin-73@163.com \\ Boqiang Cui \\ College of mining and safety \\ engineering \\ Shandong University of Science and \\ Technology \\ Qingdao, China \\ 563001309@qq.com
}

\author{
Kai Wang \\ College of mining and safety \\ engineering \\ Shandong University of Science and \\ Technology \\ Qingdao, China \\ 984237070@qq.com \\ Ruyu Yan \\ College of mining and safety \\ engineering \\ Shandong University of Science and \\ Technology \\ Qingdao, China \\ 136036335 @qq.com
}

\begin{abstract}
From the point of view of sustainable development, the durability of mine cemented paste backfill(CPB) structure has become more and more important. This paper mainly introduces the research status of the durability of CPB from the aspects of impermeability, heat resistance and chemical corrosion resistance. The main factors affecting the durability of CPB are summarized from the aspects of aggregate, cement and mixing water. And the measures for increasing the durability of the CPB were comprehensively reviewed. The results showed that the sulfate attack was the more serious problem and the temperature effect was second. The mineral composition and particle size distribution of the aggregate were the main factors affecting the performance of the CPB. Different cement varieties would provide different early strength, and the mixing water has a significant effect on the conveying performance of the CPB; adding active aggregate can replace the cement and increase the later strength of the CPB; selecting high-quality cement can significantly increase the early strength of the CPB and improve Anti-erosion performance; adding water reducing agent can reduce mixing water, improve the fluidity of the CPB and the conveying capacity in the pipeline, and improve the impermeability of the CPB. Provide theoretical basis for mine filling and mining engineering practice.
\end{abstract}

Keywords-CPB, durability, influencing factors, measures

\section{INTRODUCTION}

With the ever-decreasing coal resources that can be mined, under-water, under-rail, under-building, and pressurebearing water pressured coal mining has become one of the major problems faced by Chinese mining enterprises[1]. As an important part of the "green mining" system, Filling mining technology is the ideal way to solve the " under-water, under-rail, under-building, and pressure-bearing water " pressured coal mining [2].Due to the effect of downhole formation temperature, mineral oxidation heat generation, air compression and expansion and other factors, resulting in the formation of coal face high temperature, high humidity, can not be ventilated and other complex environments, filling materials in this environment will occur a series of physical, chemical or physicochemical reactions, which may reduce the durability of the $\mathrm{CPB}$; on the other hand, due to damage to the filling material and structural repairing, the remedial costs are increasing, people are paying more and more attention to thefilling material life cycle. Recognizing that the durability of materials is closely related to the ecological environment, prolonging the service life of materials is an ecological means of protecting natural resources. These factors make engineers pay more and more attention to the durability of filling materials. Therefore, it is necessary to study the durability of the CPB prior to the coal mine onsite application of filling[3].

In this paper, based on the analysis and summarization of the relevant achievements of durability research of CPB at home and abroad, summarize the main factors affecting the durability of CPB and the main measures for improving the durability of $\mathrm{CPB}$, and their impermeability, high temperature resistance and chemical resistance are also summarized.

\section{DURABILITY STUDY OF CPB}

The durability of $\mathrm{CPB}$ refers to the ability of $\mathrm{CPB}$ to resist various external damage factors under actual use conditions without damage and maintain the integrity of the appearance. At present, the research on filling and reclaiming at home and abroad mainly focuses on the filling technology, but neglects the influence of the underground space environment on the CPB. In high-pressure water mines, $\mathrm{CPB}$ into underground goafs is affected by many factors such as environmental temperature and chemical corrosion etc.(Fig. 1) 


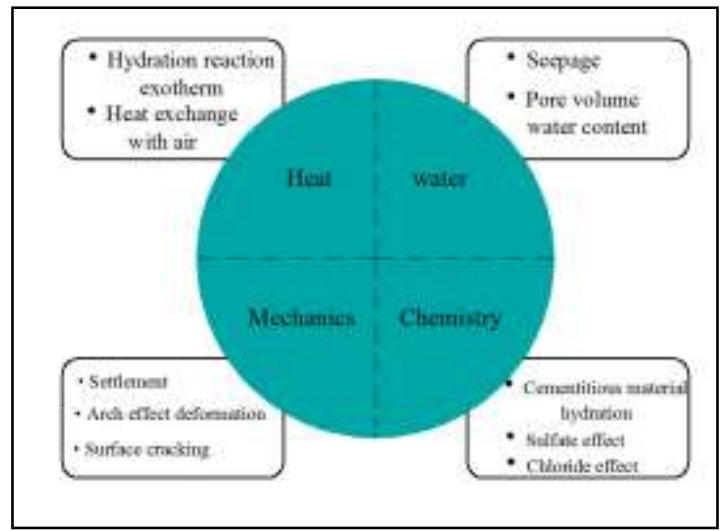

Fig.1 Multi-field erosion environment diagram of CPB

\section{A. Impermeability}

Filler slurry is a heterogeneous geotechnical material that tends to form large continuous pores. Under certain conditions, the water between the solid frameworks of the slurry flows under the action of gravity The phenomenon that water flows through the pores is called permeation or seepage.And the property of the filling slurry permeated by water is called permeability. Due to the different pore ratios of the fillers, the irregular size and shape of the pore crosssection, the penetration of water is a very complicated phenomenon. The permeability of the filler slurry directly affects the properties of its settling, hardening, mechanics, etc. The good strength parameters depend to a certain extent on its permeability.

In the 1980s, Sun[4] began to test the permeability of tailings backfill, experiments show that the permeability coefficient of the backfill is determined by the porosity, specific surface area and mineral composition. The addition of electrolytes and flocculants can increase the permeation rate. Therefore, addition of electrolytes and flocculants in the tailings filling process not only increases the permeation rate of the backfill, but also solves the problem of segregation of the cement and stratification of the tailings. Deng[5] calculated the permeability coefficient of the slurry under different conditions according to Darcy's law, and analyzed the change law of permeability. The results showed that cement content (mixing ratio) and concentration have significant influence on slurry permeability. When the concentration is the same, the permeability coefficient increases with the decrease of the water-cement ratio. When the ratio is the same, the permeability coefficient increases with the decrease of the concentration. Rui M. Pokharel[6] studied the influence of the permeability of CPB by adding sulphates, and found that at a certain temperature, the permeability of CPB will appear as the initial concentration of sulphate increases. Reduce the increase after the phenomenon. Li, K[7] proposed a mathematical model by using porosity as the only input parameter to approximately calculate the water permeability and more easily obtain the influence of various factors on the permeability. Liu R, Xiao $\mathrm{H}[8]$ added nano-silica to fillers with different water-cement ratios respectively and test the permeability coefficientThe results showed that nano-silica can significantly increase the CPB permeability when the water ash was relatively low.

When the tailings sand is used as a filling material, it is required that the tailings have good water permeability so that the filling material can be quickly dehydrated in the stope. Whether the tailings have good water permeability is an important criterion for tailings used as fillers. Good permeability can shorten the production cycle, reduce the pressure of the lower partition walls or man-made filter wells, and prevent sand running accidents.

\section{B. Heat resistance}

As the depth of mining increases, the downhole temperature will increase. On the other hand, due to downhole combustibles (coal dust, oil), heat sources (coal spontaneous combustion, gas explosions) and the presence of air, mine fires occur frequently and the high temperatures generated by fires can also adversely affect the durability of CPB. Walske, Megan L[9] used temperature-controlled hydration cells to study the effect of curing under combined effective stress and temperature conditions on the smallstrain stiffness during the 7-day curing period, and the unconfined compression strength at the end of this stage. Through the treatment of high temperature and effective stress, the mechanical properties of CPB can be significantly improved, and that curing is performed only inan effective stress or ambient temperature. Fall, Mamadou[10] study the effect of curing temperature and atmospheric temperature on the reactivity and main mechanical properties (strength, elastic modulus, and stress-strain behavior) of CPB by experimental methods. The results showed that the reactivity of CPB is related to temperature, and the reactivity increases with the increase of atmospheric temperature. However, when the temperature is high, the durability of the CPB is disadvantageous. Xiong[11] in order to study the effect of high temperature on the strength and deformation characteristics of $\mathrm{CPB}$, the compressive strength and elastic modulus of the filled pastes decreased by about $50 \%$ from the initial when the temperature reached $300^{\circ} \mathrm{C}$. Obviously, the effect of high temperature on the durability of CPB is very serious. Han Fanghui and Liu Juanhong[12]studied the effect of temperature on the microstructure and strength of hardened mortar in cement-slag composite cementitious materials. The results show that the temperature has little effect on the degree of hydration of pure cement, but the high temperature $\left(60^{\circ} \mathrm{C}\right)$ reduces the post-compressive strength of pure cement paste. $\mathrm{Wu} \mathrm{[13]} \mathrm{found} \mathrm{that} \mathrm{the} \mathrm{temperature} \mathrm{has} \mathrm{a}$ significant effect on the stress-strain relationship and elastic modulus of CPB. The increase in temperature has an effect on the degree of hydration, resulting in an increase in compressive strength and elastic modulus.

Another study showed that[14] mine backfill temperature is an important parameter that should be considered in the mine filling operation. When the temperature does not reach the decomposition temperature of the hydrate within the paste, a short time temperature increase contributes to the durability of $\mathrm{CPB}$, as the temperature increases and the time increases, the negative effects occur gradually .

\section{Chemical attack}

\section{1) Sulfate attack}

The CPB is a mixture of cementitious materials, aggregates and water that are stirred and mixed in definite proportions, and is pumped through a filling pipeline to a cemented body formed by hardening in the underground goaf. The addition of sulphur-containing minerals, mixing waterand retarders all contribute to the increase of sulphate content in CPB[10]. When the sulfate present in the well enters the $\mathrm{CPB}$, it chemically reacts with 
cement hydration products such as $\mathrm{Ca}(\mathrm{OH})_{2}$ and $\mathrm{C}-\mathrm{S}-\mathrm{H}$ gels to form expansive salts, which cause swelling and cracking or softening of the surface layer. The cracks accelerate the infiltration of erosive water containing sulfates and other ions, exacerbating the further destruction of the CPB. Qian [15] analyzed in detail the changes in sulfate content in different types of Portland cement and pointed out that the content of $\mathrm{SO}_{4}{ }^{2-}$ in cement in China is relatively low, making it impossible for sulfate in cement to fully exert its positive effect, but also increased the difficulty of reducing the potential harm of sulfate. Sun [16] established a creep model of CPB materials under sulphate corrosion conditions through experiments. It was found that when the stress of the CPB is high, accelerated creep destroythe test piece, and the sulphate corrosion effect will seriously affect the filling effect. Li [17] used mechanical experiments to analyze the early performance of cemented backfills in different sulphate environments by qualitative, quantitative and statistical analysis methods. The sulfte has a significant effect on uniaxial compressive strength, elastic modulus and damage proces of CPB; M Fall, Pokharel $M$ et al.[18]tested conductivity monitoring on CPB samples with different sulfate contents. The results show that sulfate has a significant effect on the early strength and self-drying of CPB. Sulfate can have a positive or negative impact, which leads to an increase or decrease the strength of the CPB. Jiang H, Aldhafeeri Z[19-20], tested the strength of the single pumping compressive strength by adding different concentrations of brine to the paste in a sub-zero environment for $0.25,1,2$, and 4 hours. The results showed that under freezing conditions, paste hydration products are affected by salt concentration, and the strength of CPB decreases with increasing salt concentration.

Peng and Zhang [21] have shown through experiments that under certain conditions, sulfate can be used as an early strength agent for CPB. When the filling material contains a certain proportion of slag, the cement-slag hydration system can maintain a high alkaline environment during the hydration process, fully stimulate the potential activity of the slag, promote the pozzolanic reaction, and the cement filler significantly increase in early strength characteristics. In addition to alkali activation, sulfate can also be used as a slag cement activator to increase the strength of $\mathrm{CPB}$ and optimize the pore structure.

\section{2) Chloride Erosion}

The damage to the ecological environment during mining is mainly influence the mine water on the mining process[22]. Mine water containing a variety of complex ions is used for mixing water in the goaf filling material, resulting the CPB is in a complex corrosive medium environment. Li,Zhao [23-24] have found that although there are significant differences in mine water components in the goafs in the different mines, most of them are rich in $\mathrm{CO}_{3}{ }^{2-}, \mathrm{SO}_{4}{ }^{2-}, \mathrm{Cl}^{-}$, and $\mathrm{Ca}^{2+}, \mathrm{Mg}^{+}$, $\mathrm{Na}^{+}$, etc. $\mathrm{Cl}^{-}$is the most common corrosive medium, and its permeability is relatively large. During the mining process, $\mathrm{Cl}^{-}$enters the interior of the water-rich filling material along the fractures of the filling material and chemically reacts with hydrates such as calcium sulfo-aluminate, affecting the chemical structure and stability of hardened body of the filling material. Gao, Liu [25], etc. Through scanning electron microscopy (SEM), energy disperse spectroscopy (EDS) and X-ray diffraction (XRD) and other experimental means, to explore the chlorine salt on the water-rich filling material corrosion and deterioration mechanism. The results show that the compressive strength of the CPB after immersion in the chloride solution with $10 \%$ mass fraction decreases significantly with the immersion time, which indicates that the chloride solution has corrosive effect on the water-rich filling material. Sun [26] explored the creep law of paste filled with chloride after different time corrosion. In the early stage of corrosion, the creep deformation of the eroded $\mathrm{CPB}$ is smaller than that of non-corrosion; the corrosion time is prolonged. The creep deformation of the CPB gradually increases; under the conditions of long-term corrosion and high stress levels, the phenomenon of accelerated creep will occur in the CPB.

Mohammed T[27]believes thatit will be chemically combined or physical adsorption after chlorine ions enter the cement-based materials: some of the chloride ions will react with certain chemical salts of cement, some will adsorb on the wall and hydration products. These two conditions are collectively called chloride ion bonding. They are processes in which the cement-based material cures chloride ions to some extent in some cement phases and proceeds in its pore solution.

\section{3) Acid and alkali corrosion}

The expansion and cracking of the acidic material on the CPB is not caused by a complex chemical reaction, but by dissolving some of the soluble cement hydration products, destroying the dense structure of the paste and losing the cohesion between the concrete components. Different kinds of acids have different destructive effect and destruction rates to the cement hydration products, but the continuous effect results in destruction of the CPB. The addition of alkaline substances is helpful for the durability of the CPB. Because calcium hydrates such as hydrated calcium silicate and ettringite in the CPB are in a stable state in the higher alkali solution. The increasing in $\mathrm{pH}$ value is more conducive to the stable presence of the hydrated product of the filling test.. At present, there is less research on such erosion. Liu [28] studied the effect of acidic environment on water-filled materials through experiments. The results showed that the compressive strength of water-rich filling materials after immersed in hydrochloric acid solution with $\mathrm{pH}$ of 1 and 3 for 180 days was lower than that of standard curing for 28 days respectively. $88.8 \%$ and $58 \%$ were reduced by $68 \%$ after soaking in a sulfuric acid solution with a $\mathrm{pH}$ of 3 ; the strength was reduced to zero after soaking in a sulfuric acid solution with a $\mathrm{pH}$ of 1 ; the sulfuric acid solution had stronger corrosion effects on the water-rich filling material than the hydrochloric acid solution. Gao [29] immersed the filling material in sodium carbonate solution, the compressive strength decreased significantly with the soaking time, indicating that the carbonate solution has a corrosive effect on the water-rich filling material. Wang and Liu [30] simulated the acid-base environment of the CPB by using $\mathrm{HCl}$ and $\mathrm{NaOH}$ solutions. Tests showed that when the test specimens of the filling body were soaked in $2 \% \mathrm{HCl}$ solution, the filling body reacted violently: the filling body bubbles are generated on the surface, large areas fall off from the surface, leakage of aggregates occurs, and the solution has a foul odor. These phenomena indicate that a strong chemical reaction occurred between the initial $\mathrm{HCl}$ solution and the specimen of the CPB, and the compressive strength decreased with time; for alkali erosion, when the specimen of the $\mathrm{CPB}$ was soaked in a $2 \% \mathrm{NaOH}$ solution for a certain period of time, the strength of the specimens did not change significantly, and the apparent changes were not obvious. As 
the soaking time increased, the compressive strength of the specimens increased. Therefore, the soaking with alkaline solution is beneficial to the increase of compressive strength of the test specimens of the CPB [31].

\section{CPB DURABILITY MAIN FACTORS}

The durability of backfills is affected by many factors. As people continue to deepen the research on $\mathrm{CPB}$, the understanding of these influencing factors is becoming clearer, and the influence factors can be roughly divided into cement, aggregate, and mix. Water and conservation of the environment and other four categories. The durability of CPB structure is affected by many factors. With the deep research on $\mathrm{CPB}$, people have become more aware of these influencing factors. The influencing factors can be roughly divided into aggregates, cementitious materials, and mixed water. And conservation of the environment in four categories.

\section{A. Aggregate}

Aggregate is the main part of the CPB and occupies the largest proportion. It is generally wastes such as fly ash, coal gangue, construction waste and tailings. The impact of aggregate on the properties of CPB can be divided into two parts: physical and chemical, that is, the mineral composition and particle size distribution of the aggregates. Physically speaking, aggregate grading is an important factor influencing the strength and other properties of CPB. The gradation refers to the distribution of the material's particle size from small to large, and the parameters of the aggregate level pairing filling and filling the workability, flowability and permeability coefficient have a certain influence [32]. From a chemical point of view, the smaller the particle size of the aggregate, the greater the surface area, and the more cement needed to achieve the same strength. In addition, properly reducing the content of very fine particles in the aggregate can reduce the amount of cement and increase the strength of the CPB.

\section{B. Cement}

Ordinary Portland cement is the most commonly used cementitious material for CPB [33]. The industrial byproducts such as grinding blast furnace water quenched slag, red mud, desulfurized gypsum and fly ash with certain pozzolanic activity or hydraulic properties are also often used as one of the binder components, in which slag and fly ash are mixed as a mixture, because with higher pozzolanic activity, cement can be partially or totally replaced [34-35], thus achieving the goal of reducing production costs. In general, increasing the amount of gelling material can improve the compressive strength, impermeability, and erosion resistance of the filled paste [36], which has a significant effect on the durability of the $\mathrm{fCPB}$.

\section{Mixing water}

The strength of the $\mathrm{CPB}$ is a result of the hydration product produced by the hydration reaction of the cementitious material. Water acts as a place and reactant for $\mathrm{CPB}$, and also serves as a carrier for the filling material. Its influence is mainly reflected in the water content and the water composition. The slurry concentration of the filling body has an important influence on the transport performance of the filling slurry and the development of the
CPB strength. As the water content of the filling slurry increases, the slurry concentration decreases and the slurry has better transportability. However, as the water content increases, the underground drainage volume increases, the time for filling the paste increases, the pore structure becomes loose, and the strength decreases. According to the hydration process of the cementitious material, the amount of water in the cement hydration process is very small. Therefore, under the premise of meeting the transportation requirements, the moisture content of the filling slurry should be reduced as much as possible. With the increase of the slurry concentration, the flow characteristics of the CPB gradually change qualitatively. That is, when the $\mathrm{CPB}$ concentration rises to a certain level, the $\mathrm{CPB}$ can be changed from solid-liquid two-phase into a structural fluid with similar characteristics. At the same time, the settlement and segregation are weakened. Due to the lower water content and the shorter hardening time, the water pores left by the free water in the CPB are reduced, and the strength is rapidly increased, which is favorable for the early performance of the CPB. Paste filling water is generally mine pit water or industrial water. C. Wang [37] pointed out that, in general, the $\mathrm{pH}$ of mine water is generally less than 5.5 , which is acidic, and it is easy to corrode the CPB if it is filled. Adding a proper amount of alkaline substances to the paste can relieve this erosion to some extent.

\section{IMPROVE THE CPB DURABILITY MAIN MEASURES}

\section{A. Add active aggregate}

Fly ash has a good volcanic ash effect because of its presence of a large number of active ingredients $\mathrm{SiO}_{2}$ and $\mathrm{Al}_{2} \mathrm{O}_{3}$. Fly ash is one of the most commonly used filling materials in mines. Zhou [38] used fly ash from a nearby power plant to produce a toothpaste slurry that did not require dehydration, and its compressive strength was significantly enhanced in the later period. Peng [39] showed that when the water-cement ratio is the same, with the increase of fly ash content, the compressive strength of the $\mathrm{CPB}$ first increases and then decreases. When the fly ash content is $20 \%$, the decrepit Degrees and compressive strength reach maximum values. The strong pozzolanic activity of fly ash results in a large consumption of cement hydration product $\mathrm{Ca}(\mathrm{OH})_{2}$, a decrease in the reaction between $\mathrm{SO}_{4}{ }^{2-}$ and $\mathrm{Ca}(\mathrm{OH})_{2}$, and a controlled generation of expandable product, so that for different concentrations in areas with different ambient temperatures, sulfate erosion can also be effectively controlled. On the other hand, fly ash can be an appropriate substitute for cement, saving costs, is a very ideal material.

\section{B. Select the appropriate cement type}

When the cement and water are mixed, a hydration reaction will immediately occur to form a cement slurry. As the hydration reaction continues, the cement slurry will gradually become rigid, condense, and finally harden with a certain strength. Hydration of cement is a complex process of physical and chemical change. By choosing the right cement type, the durability of the CPB can be effectively improved. Kesimal et al.[40] showed that the strength of a test block made of $14 \%$ volcanic ash had a strength loss of $42 \%$ during the 180 to 360 days of age, and a cement with a volcanic ash content of $29 \%$. The resulting test block loses only $9 \%$ of its intensity at the same time. Therefore, the higher content of 
volcanic ash, the more effective anti-sulphate erosion. $\mathrm{Li}$ et al.[41] used mineral cement and ordinary portland cement, respectively, as cementing materials for tailings cemented CPBs. The test results showed that the CPB test block made of mineral cement was better than ordinary portland cement. The strength of the test block made is about $40 \%$ higher. This is because mineral cement contains more volcanic ash, which reduces the effect of sulfate on cement erosion. Slag cement and pozzolan cement have a good pozzolanic effect, that is, they have more active components and react with cement hydration product $\mathrm{Ca}(\mathrm{OH})_{2}$ to generate more $\mathrm{CSH}$ with gelling properties, thereby increasing $\mathrm{CPB}$ erosion resistance.

\section{Add high quality water reducer}

There are many varieties of additives, and the range of application is more and more extensive, but water reducer is one of the most used additives. An effective way to increase the $\mathrm{CPB}$ strength while reducing the filling cost is to increase the mass concentration of the CPB. However, in engineering practice, as the paste transport concentration increases, the transport performance will decrease. That is, when the paste concentration is increased, the paste slump decreases, and the fluidity will inevitably decline. This will have a greater impact on the transfer performance of CPB. Therefore, in order to increase the $\mathrm{CPB}$ concentration, it is also necessary to obtain good flow characteristics of the high-concentration paste required by the filling process, and to develop a highrange water-reducing agent. In the research and application of mine filling, water reducing agent can effectively solve this problem. Wang and Shi[42] added $1 \%$ water reducer to the filling slurry, so that the concentration of the filling slurry was increased from $78 \%$ to $82 \%$ to $83 \%$, while the slurry maintained good fluidity. Due to the increase of the slurry mass concentration, the sedimentation rate of the CPB is reduced, which helps to improve the overall stability of the $\mathrm{CPB}$. Water-reducing agent is a kind of surfactant, which can greatly reduce the amount of water used to make $\mathrm{CPB}$ and increase the compactness of CPB. The incorporation of the admixture is to increase the compactness of the CPB, thereby effectively preventing the intrusion of $\mathrm{SO}_{4}{ }^{2-}$, and improving the erosion resistance of the CPB.

\section{DURABILITY OUTLOOK}

In summary, the study of the durability of CPB structure is an important issue for mine filling and mining. Because the environment where the CPB is located is extremely complex, the following aspects are summarized to analyze the existence of paste paste structural durability. Problems and next research ideas.

(1) Due to the different distribution locations of mines, the environmental differences are relatively large. It is possible to test the frost resistance of mine CPB in different regions to analyze the various mechanical properties of CPB. There are few studies in this area and it needs to be further studied research.

(2) The current addition of admixtures has been very common, but it has many types and the effect is not good. In the process of admixture research, under the premise of ensuring cost control, it has shown various effects, thereby improving the durability of the CPB.
(3) For the above research on the structural durability of $\mathrm{CPB}$, most of them are only considered for a single factor. However, in the real underground environment, the CPB are subject to multiple erosion and should be considered in consideration of their environment.

(4) The durability of the CPB depends on the filling material. Therefore, the development of a new type of material ratio is one of the problems to be solved in the mine filling and mining technology.

\section{CONCLUSION}

(1) Reviewing the impermeability, heat resistance and acid and alkali corrosion resistance of $\mathrm{CPB}$, in which the sulfate attack is more serious and the temperature influence is second;

(2) Summarize the main factors affecting the durability of CPB: aggregate, cement, and mixing water. The mineral composition and particle size distribution of the aggregate are the main factors affecting the performance of $\mathrm{CPB}$; different cement varieties will provide different early strength; and the mixing water has a significant effect on the conveying performance of $\mathrm{CPB}$;

(3) Summarize the main measures to improve the durability of the CPB. Adding active aggregate can replace cement, save cost and increase the late strength of CPB. Selecting high-quality cement can significantly increase the early strength of CPB and improve corrosion resistance; adding water reducing agent can reduce mixing water and improve CPB the fluidity and the ability to transport in the pipeline, and improve the impermeability of CPB.

\section{REFERENCES}

[1] Q. Minggao, X. Jialin, W. Jiachen. "Further on the sustainable mining of coal," Journal of China Coal Society, Vol.1, pp. 1-13,2018.

[2] W. Aixaing, W. Yong, W. Hongjiang. "Status and Prospects of the Paste Backfill Technology," Journal of China Metal Mine, Vol.7, pp. 1-9, 2016.

[3] Z. Huaxing, G. Weijia, X. Yanchun et al. "Three-underground" new coal mining technology. Xuzhou: China University of Mining and Technology Press, 2008.

[4] S. Zhongran. "Study on permeability of tailings backfill," Gold, vol. 1982: pp. 1-5.

[5] D. Daiqiang, G. Yongtao, Y. Zhongliang, W. Shunchuan, Z. Weiya. "Study on permeability of cement-graded tailings filling materials," Journal of Xi'an University of Architecture \& Technology, vol. 41: pp. 694-698, 2009.

[6] M. Pokharel, M. Fall. "Combined influence of sulphate and temperature on the saturatedhydraulic conductivity of hardened cemented paste backfill," Cement and Concrete Composites, vol. 38: pp.21-28,2013.

[7] L. Kai, P. Stroeven, M. Stroeven. "Estimating permeability of cement paste using pore characteristics obtained from DEM-based modelling," Construction \& Building Materials, vol. 126: pp. 740-746, 2016.

[8] L. Rui, X. Huigang, L. Hui. "Effects of nano-SiO 2, on the permeability-related properties of cement-based composites with different water/cement ratios," Journal of Materials Science, vol. 53: pp. 4974-4986, 2018.

[9] M. L. Walske, H. McWilliam, J. Doherty, A. Fourie. "Influence of curing temperature and stress conditions on mechanical properties of cementing paste backfill," Canadian Geotechnical Journal, vol.53: pp. 148-161, 2016.

[10] M. Fall, M. Pokharel. "Coupled effects of sulphate and temperature on the strength development of cemented tailings backfills: Portland 
cement-paste backfill," Cement and Concrete Composites. vol.32: pp. 819-828, 2010.

[11] X.Rui. "The influence of high temperature on strength and deformation characteristics of cementing backfill," Journal of China Mining Technology, Vol.6, pp. 18-21. 2015.

[12] H. Fanghui, L. Juanhong. "Effect of temperature on hydration of composite binder containing slag," Journal of Silicate, vol.44:pp. 1071-1080, 2016.

[13] W. Aixiang; W. Yong, Z. Bo, S. Jiaua. "Effect of initial backfill temperature on the deformation behavior of early age cemented paste backfill that contains sodium silicate," Advances in Materials Science and Engineering,vol. (1075): pp. 1-10, 2016.

[14] M. Pokharel; M. Fall. "Combined influence of sulphate and temperature on the saturated hydraulic conductivity of hardened cemented paste backfill," Cement and Concrete Composites,vol. 38: pp. 21-28, 2013.

[15] Q. Jue Shi, W. Yingchun, D. Lingxi. "The type and role of sulfate in Portland cement," J. Journal of the Chinese Ceramic Society, vol.42: pp. 169-177, 2014.

[16] S. Qi, L. Xilin, M. Qianwen. "Study on Creep Properties of Paste Filling Material by Sulfate Corrosion," China Safety Science and Technology, vol.11: pp. 12-18, 2015.

[17] L. Wenchen, "Effect of sulfate on the early performance of cemented backfill and its mechanism," China University of Mining and Technology, Beijing, 2016.

[18] Z. Aldhafeeri, M. Fall, M. Pokharel, Z. Pouramini. "Temperature dependence of the reactivity of cemented paste backfill," Applied Geochemistry, vol.72: pp. 10-19, 2016.

[19] J. Haiqiang, F. Mamadou. "Yield stress and strength of saline cemented tailings in sub-zero environments: Portland cement paste backfill," International Journal of Mineral Processing, vol.160: pp. 68-75, 2017.

[20] A. Zaid, F. Mamadou. "Sulphate induced changes in the reactivity of cemented tailings backfill," International Journal of Mineral Processing, pp.166, 2017.

[21] P. Jiahui, Z. Guihong, B. Leng. "Sulfate excitation and slag modified anhydrite adhesive ," Silicate Bulletin, vol.04: pp.837-842, 2008.

[22] W. Ping. "Research status of domestic coal mine water treatment technology," Tongji Coal Science and Technology, vol.2008 : pp.1-7.

[23] L. Fuqin, Y. Jing, H. Xuwen. "High salinity degree of high ferromanganese mine water reuse treatment process," Journal of China University of Mining \& Technology, vol.35: pp.637-641, 2006.

[24] Z. Fenghua, S. Hongfu, L. Wensheng. "Migration characteristics of harmful elements in acid mine water of coal mines," Journal of China Coal Society, vol32: pp. 261-266, 2007.

[25] G. Meng, L. Juanhong, W. Aixiang, Z. Xianghui. "Mechanism of Corrosion and Degradation of Water-rich Filling Materials in Typical Chloride Environment," Journal of Central South University (Natural Science), vol.47: pp. 2776-2783, 2016.

[26] S. Qi, L. Xilin, S. Wei, M. Qianwen. "Effects of Chloride Corrosion on Creep Properties of CPB," Journal of Experimental Mechanics, vol.30: pp. 231-238, 2015.
[27] T. U. Mohammed, H. Hamada. "Relationship between freechloride and total chloride contents in concrete," Cement andConcrete Research, vol.33: pp. 1487-1490, 2003.

[28] L. Juanhong, G. Meng, W. Aixiang. "Mechanism of corrosion and deterioration of water-rich filling materials in acid environment," Journal of Engineering Sciences, vol.38: pp.1212-1220, 2016.

[29] G. Meng, L. Juanhong, W. Aixiang. "Corrosion and deterioration mechanisms of water-rich filling materials in carbonate solutions," Journal of Engineering Sciences, vol.37: pp. 976-983 , 2015.

[30] W. Qifeng, L. Yin, Z. Haoqiang, J. Ning. "Experimental study on durability of gypsum body filling materials," Coal Mining, vol.19: pp.3-6, 2014.

[31] Z. Hongjun, C. Haili, J. Demin. "Special Concrete and New Concrete," Beijing: Chemical Industry Press, 2004.

[32] W. Lijiu, L. Hui. "Research status and development trend of gradation design theory of mineral materials," Highway, vol. 01: pp. $170-175,2008$

[33] H. Wolfgang, H. Jiping. "Various factors that affect the strength of fine-grained cement fillers," Foreign metal ore mining, vol.04: pp. 6169, 1983.

[34] G. Shujie, Y. Wen, L. Keqing. "Preparation of Mine Filling Material and Its Hydration Mechanism with Hydroponics Secondary Nickel Residues," Journal of The Chinese Ceramic Society,vol.05: pp. 612619,2013

[35] H. Di, Y. Wen, Z. Liping. "Effect of activator on properties of red mud-slag cemented filling material," Mining Research and Development, vol.04: pp. 13-16+51, 2011

[36] F.L.Aylmer. "Cement ProPetries related to the behavior of cemented fill," /Proc.of the Jubilee SymP onMine Filling Mt.Isa/Queensland, ; Austral. Inst.Min. Met. vol.S, pp.1-282. 1973.

[37] C. Wang, E. Villeascusa. "Influenee of water salinity on the properties of cementedtailings backfill," Transcations of the instittuion of mining and meatllugryseetion A-mining technology, vol.110: pp.62-65, 2001

[38] Z. Huaqiang, H. Chaoxi, S. Xikui. "Solid waste paste filling unmoved village coal mining," Journal of China University of Mining \& Technology, vol.33: pp.154-156, 2004.

[39] P. Dexin. "Influence of water-cement ratio and fly ash content on sulfate resistance of concrete," Hunan Transportation Science and Technology, vol.02: pp. 67-68+162, 2014.

[40] A. Kesimal, E. Yilmaz, B. Ercikdi, I. Alp and H. Deveci. "Effect of properties of tailings and binderon the short- andlong- term strength and stability of cemented paste backfill," Materials Letter, vol.59: pp.3703-3709, 2005.

[41] J. Li, E. Villaescusa, D. Tyler and T. McGrath. "Factors affecting the filling quality of underground mines," Proceedings of the 8th International Conference on Fill Mining. Mining Research and Development, vol.24: pp. 187-191, 2004.

[42] W. Xinmin, S. Lianggui, X. Zhizheng, X. Weiguo, G. Chunhua. "Mechanism and application of water reducing agent in filling slurry," Metal Mining, vol.04: pp.11-13+37, 2004. 